\title{
The profile of patients followed at the Neuroimmunology Clinic at UNIFESP: 20 years analysis
}

O perfil de pacientes atendidos no setor de Neuroimunologia da UNIFESP: análise de 20 anos

Denis Bernardi Bichuetti, Alessandra Billi Falcão, Fernanda de Castro Boulos, Marilia Mamprim de Morais, Claudia Beatriz de Campos Lotti, Manuela de Oliveira Fragomeni, Maria Fernanda Campos, Nilton Amorim de Souza, Enedina Maria Lobato Oliveira

\section{ABSTRACT}

Objective: To describe the clinical activities at the Neuroimmunology Clinic of the Universidade Federal de São Paulo (UNIFESP) from 1994 to 2013. Method: The final diagnosis of all patients that attended the center was reviewed and established upon specific guidelines for each disease. The number of total appointments and extra clinical activities (reports and prescriptions) were also analyzed, as are part of routine activities. Results: 1,599 patients attended the Clinic from 1994 to 2013: 816 with multiple sclerosis (MS), 172 with clinical isolated syndromes, 178 with neuromyelitis optica (NMO), 216 with other demyelinating disease, 20 with metabolic disorder, 42 with a vascular disease and 155 with other or undetermined diagnosis. A mean 219 outpatient visits and 65 extra clinical activities were performed monthly. Conclusion: We identified that $15 \%$ of patients seen have NMO. As patients with NMO have a more severe disease than MS, this data may be important for planning local health care policies.

Keywords: multiple sclerosis, neuromyelitis optica, epidemiology, Sao Paulo.

\section{RESUMO}

Objetivo: Descrever a casuística de pacientes atendidos no setor de Neuroimunologia da Universidade Federal de São Paulo (UNIFESP) de 1994 a 2013. Método: Analisamos o diagnóstico final de todos os pacientes atendidos de 1999 a 2013, sendo o diagnóstico revisado na última consulta e estabelecido de acordo com os critérios específicos para cada doença. O volume de atendimentos clínicos e não clínicos (relatórios e receitas) foram contabilizados para avaliar a carga de trabalho da equipe. Resultados: 1.599 pacientes foram avaliados: 816 com esclerose múltipla (EM), $172 \mathrm{com}$ síndromes clínicas isoladas, $178 \mathrm{com}$ neuromielite óptica (NMO), 216 com outras doenças desmielinizantes, 20 com doenças metabólicas, 42 com doenças vasculares e 155 com outros diagnósticos ou diagnósticos indefinidos. Identificamos uma média de 219 consultas e 65 solicitações de relatórios por mês. Conclusão: Identificamos que 15\% dos pacientes atendidos tem NMO. Por ser uma doença mais incapacitante que a EM estes dados podem ser importantes para o planejamento de políticas de saúde locais.

Palavras-chave: esclerose múltipla, neuromielite óptica, epidemiologia, São Paulo.

Multiple sclerosis (MS) and neuromyelitis optica (NMO) are the most important and common inflammatory autoimmune diseases that affect the central nervous system (CNS) and can lead to sustained neurologic disability and financial burden for the society ${ }^{1,2}$. Both diseases can cause visual impairment, pyramidal deficits, sensation loss, neuropathic pain, coordination problems, gait impairment and cognitive problems (more MS than NMO). While MS has a

\footnotetext{
Universidade Federal de São Paulo, Departamento de Neurologia, Sao Paulo SP, Brazil.

Correspondence: Denis Bernardi Bichuetti; Universidade Federal de São Paulo, Departamento de Neurologia; Rua Botucatu,740; 04023-900 São Paulo SP, Brasil; E-mail: bichuetti@unifesp.br

Disclosures: Bichuetti DB has received speaking honoraria from Bayer Health Care, Merck Serono and Biogen Idec, serves in advisory board meetings by Merck Serono and Sanofi Genzyme and travel expenses to scientific meetings from Bayer Health Care, Merck Serono and TEVA.

Boulos FC is an employee at Novartis.

Oliveira EML received compensations for participating in meetings sponsored by Bayer Health Care, Biogen Idec, Merck Serono, and Teva Pharmaceuticals and serves in advisory board meetings by Biogen Idec, Novartis and Genzyme.

Souza NA had received travel expenses to scientific meetings from Bayer Health Care, Merck Serono and TEVA.

Falcão AB, Lotti CBC, Campos MF Morais MM and Fragomeni MO have nothing to disclose

This is not an industry-sponsored study.

Conflict of interest: There is no conflict of interest to declare.

Received 29 June 2014; Received in final form 16 November 2014; Accepted 05 December 2014.
} 
stepwise or continuously progressive initial presentations, known as relapsing remitting multiple sclerosis (RRMS) or primary progressive multiple sclerosis (PPMS), NMO does not have a progressive clinical course and neurologic impairments are solely relapse dependent ${ }^{3,4,5}$. The diagnosis of both diseases are made with a combination of clinical signs and symptoms, specific magnetic resonance imaging criteria, cerebrospinal fluid analysis, electrophysiological studies and the exclusion of other causes for the specific symptoms ${ }^{6,7}$. For NMO there is also a specific serum antibody that targets the aquaporin- 4 water channel at the blood-brain-barrier available for disease confirmation ${ }^{7}$, also called NMO-IgG.

The prevalence of MS rises in higher latitudes, ranging from $20 / 100,000$ to nearly $90 / 100,000$ in the northern hemisphere countries, possibility related to sun exposure, genetics of specific populations in these areas and others yet unknown environmental factors ${ }^{8,9}$. The prevalence of MS in the city of Sao Paulo and Belo Horizonte, two major Brazilian cities, are estimated around $15 / 100,000^{10}$ and $18 / 100,000$ inhabitants ${ }^{11}$ and, although they might not reflect the real national data, they are the most accurate information on the theme to date.

The prevalence of NMO, on the other hand, ranges from 0.5 to 4.4/100,000 inhabitants in North America and Europe, but this data is unknown in Brazil. NMO affects more frequently African-Descendants and Asian populations ${ }^{12}$ than Caucasians, and since Brazil is a country of mixed ethnic population its prevalence might be higher in Brazil than in other countries. This is supported by studies that disclosed specific genetics risk factor for NMO in Brazil ${ }^{13,14,15}$.

Additionally, in North America and European countries MS is known to be the main cause of disability and retirement in people under 50 years old ${ }^{16}$ and, although this information is not clearly available for Brazil, national studies disclose that patients with NMO have a more severe disease than patients with RRMS, including higher risk of becoming wheelchair bound and dying of a demyelinating disease ${ }^{12}$, which reinforces the need of information on these disease, as it may have social and economic impact. It is important to state that both diseases are treatable and that neurologic disability can be avoided or postponed with specific medications, some of them available from the Sistema Único de Saúde (SUS), the Brazilian Public Health Care System ${ }^{17}$.

The aim of this study is to present the 20-year descriptive analysis of patients attending the Neuroimmunology Clinic of the Universidade Federal de São Paulo (UNIFESP), not only regarding specific clinical diagnosis and the rate of MS and NMO, but also expose clinical background activities such as performing medical reports and filling medication prescriptions renovations, offering information that could be used by health care authorities in creating a plan of care for these patients.

\section{METHOD}

The Neuroimmunology Clinic of the UNIFESP is a public tertiary care center focused on caring for patients with multiple sclerosis and other demyelinating diseases, established in 1994, and located at Hospital São Paulo, the main general hospital at the UNIFESP complex. Since then, the center keeps a database containing all clinical, laboratory, radiological and therapeutic information of all the patients attending the clinic. All patients attending the clinic are invited to participate in a prospective registry approved by the university's institutional review board and sign a written informed consent for clinical and radiological data storage and analysis. This study is a cross-sectional evaluation of this database, encompassing all patients evaluated from 1994 to December $31^{\text {st }} 2013$.

We retrieved the final diagnosis of all patients that had an appointment at our center; the diagnosis of each subject was always reviewed at the last follow up appointment and was made according to specific guidelines at the time they were last seen. The patients are allocated in the following categories, followed by some examples:

1) Multiple sclerosis (MS): relapsing-remitting MS, primary-progressive MS and secondary-progressive MS;

2) Clinical isolated syndromes (CIS): optic neuritis, partial transverse myelitis and brainstem syndromes either with brain lesions suggestive of MS (meeting treatment criteria ${ }^{18}$ ) or not, but not meeting current criteria for $\mathrm{NMO}^{7,19}$ or other diseases;

3) Neuromyelitis optica spectrum disorders (NMO-SD): classical $\mathrm{NMO}^{7,19}$, longitudinally extensive spinal cord lesions (recurrent or single episode with positive NMO-IgG), relapsing optic neuritis (recurrent or single episode with positive NMO-IgG) or brainstem or cerebral inflammatory syndromes with positive $\mathrm{NMO}-\operatorname{IgG} \mathrm{G}^{2,20}$;

4) Other demyelinating disease: adrenoleukodistrophy, Krabbe disease and metachromatic leukodistrophy, among others;

5) Metabolic disorder: vitamin B12 deficiency, muscle metabolism disorders;

6) Vascular disease: multiple cerebral infarcts ("etat lacunaire"), spinal cord infarct and others related to cerebrovascular disease;

7) Other diagnosis: mitochondrial neurogastrointestinal encephalopathy, HTLV associated tropical spastic paraparesis, psychiatric disease, mitochondrial diseases, other degenerative disorders (multiple system atrophy and other atypical parkinsonian syndromes);

8) Undetermined: patients that we could not determine the diagnosis either due to unavailability of specific tests or inconclusive investigation.

When the diagnosis was MS and NMO, we also evaluated the number of patients that presented the first symptom before completing 18 or after 50 years of age, as these are the current literature definitions for pediatric and late onset diseases, 
respectively ${ }^{21,22}$. All patients were offered regular preventive therapies recommended and available for their diagnosis (MS or $\mathrm{NMO}$ ) at the time they were seen, which included, but were not restricted to, interferon beta, glatiramer acetate, natalizumab, fingolimod, corticosteroids, cyclophosphamide, methotrexate, azathioprine, plasma exchange and IV immunoglobulin ${ }^{20,23}$.

We also reviewed the number of total appointments as well as the number of reports requested (medical reports for job applications, early retirement, benefices for the handicapped, medication usage for international travelers and others) and medications prescriptions renewal demanded by the patients, as these are part of the "off clinic" regular patient care activities. It is important to say that the Brazilian public healthcare system, Sistema Único de Saúde (SUS), requires that all patients present a new medication prescription every three months, in order to maintain regular supply, an important part of the "off clinic" described above. Since a complete computerized system for all outpatient activity was only implemented on the second semester of 2013, the clinical activity information was evaluated from August $1^{\text {st }} 2013$ to December $31^{\text {st }} 2013$ (5 months). The intention of this report is to describe the outpatient clinic population, therefore we did not include appointments made at the emergency department nor clinical, prognostic and treatment response information, available in previous studies from our group $5,12,24,25,26,27$.

\section{RESULTS}

We identified 1,599 patients that attended the Neuroimmunology Clinic at least once from 1994 to 2013, $2 / 3$ of them with MS and NMO (Figure). We then evaluated separately only the patients with recurrent primary autoimmune demyelinating disease of the central nervous system, MS and CIS in a single group and NMO as a distinct group, revealing a total of 1,166 patients: 988 with MS/CIS (84.7\%) and 178 (15.3\%) with NMO and NMO-SD (Figure). From the totality of patients with MS, $7 \%$ presented as pediatric onset and $4 \%$ as late onset, and $4 \%$ of the patients with NMO presented as pediatric onset whereas $7 \%$ as late onset.

The activities performed by the staff from August $1^{\text {st }} 2013$ to December $31^{\text {st }} 2013$ (5 months) summed 55 clinical appointments and 16 "off clinic" activities per week (Table).

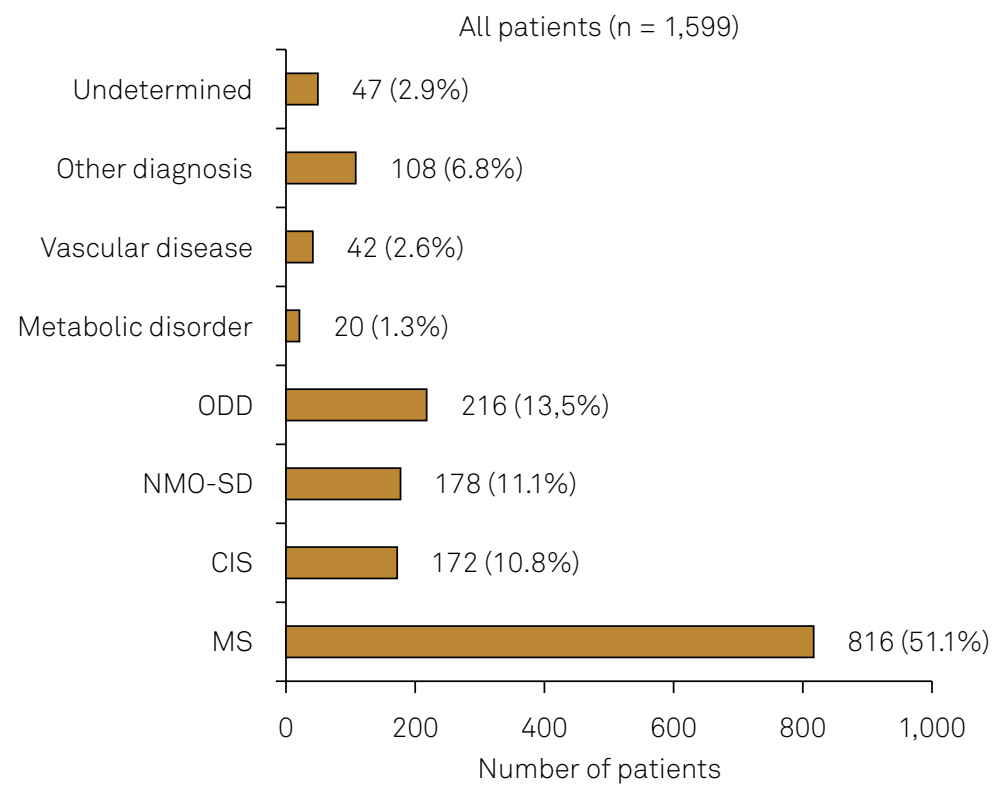

MS+CIS and NMO only $(n=116)$

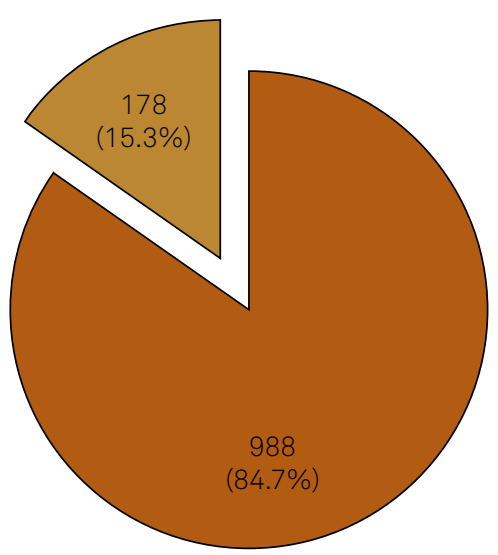

$\square$ MS $\square$ NMO-SD

Figure. Total number of patients that attended the Neuroimmunology Clinic by final diagnosis. Left: Sum by all diagnosis; Right: Recurrent primary autoimmune demyelinating disease of the central nervous system, i.e., MS and CIS in a single group and NMO-SD. MS: Multiple sclerosis (relapsing remitting and primary progressive onset of MS forms); CIS: Clinical isolated syndrome (optic neuritis, partial transverse myelitis and brainstem syndromes either with brain lesions suggestive of MS (meeting treatment criteria ${ }^{18}$ ) or not, but not meeting current criteria for NMO7,19 or other diseases); NMO-SD: Neuromyelitis optica spectrum disorders; ODD: Other demyelinating disease. Data includes patients that performed at least one appointment at the Clinic between 1994 and 2013.

Table. Outpatient visits and activities performed by the staff.

\begin{tabular}{|c|c|c|c|}
\hline & Mean by month* & Mean by week & Yearly** \\
\hline Outpatient visits* & 219 & 55 & 2,413 \\
\hline Reports and medical prescriptions $* \star \star$ & 65 & 16 & 712 \\
\hline
\end{tabular}

*Data from August $1^{\text {st }} 2013$, to December $31^{\text {st }} 2013$ (5 months). **Yearly estimative considering 11 working months. Values obtained from multiplying the "mean by month" for 11 working months, as the University seizes outpatient activities on Christmas and New Year's and national holidays. *** Only registered requests performed outside clinical appointments, as some reports and medication prescriptions are also filled during outpatient visits. 


\section{DISCUSSION}

This study discloses that $15.3 \%$ of patients with primary autoimmune demyelinating diseases of the central nervous system followed at a specialized tertiary care center in the city of Sao Paulo have NMO-SD, a number nearly 10 times higher that reported for North America or Europe ${ }^{2}$. Given that patients with NMO have a more severe disease than MS, this may have implications on health care and society costs, and should be the focus of local policies. The numbers of pediatric and late onset cases reported are similar to other national and international centers ${ }^{24,25}$.

One third of the patients evaluated at the clinic did not have MS or NMO, which is not surprising as patients are referred to us for diagnostic confirmation from primary care physicians or general neurologists ${ }^{28}$. These patients are either referred back to their primary doctors or to the specific clinic within our neurology department for follow up and treatment and this rate should not be used to evaluate the system's efficiency.

As expected in any routine medical practice, the work performed by the staff is not restricted to the time allocated in direct patient care (Table), as "off clinic" duties include regular care paperwork (prescriptions and reports), phone and e-mail answering, which are very difficult to keep track, and administrative meetings. Many medications available at the SUS, especially the ones considered of high costs, such as the ones used for the treatment of MS and NMO, needs prescription renovation every 3 months ${ }^{17}$, which increases the need for follow-up appointments in an already busy and overloaded clinic, and the creation of an extra agenda for reports and prescription refilling, as they are constantly needed in order to keep patients under regular treatment. These activities should be taken into account when planning the staff required and their working duties for a specialized service as this one.
The plan of care in our clinic is one appointment every 3 months in the first year after diagnosis and every 6 months on the following years, excepts when new symptom demand earlier and urgent evaluation. Since many patients have a concomitant follow-up with an external neurologist, either private or within their health care insurance, and come to the clinic on a yearly or as needed basis, such as medication switch or treatment reassurance, the number of outpatients visit do not exactly reflect the total work demanded by patients with NMO or MS. Thus, considering the number of outpatient visits required if these patients were $100 \%$ dependent on the UNIFESP clinic, the number of appointments offered today would not be sufficient. Furthermore, emergency service visits, the use of an infusion facility for medication administration and inpatient care were also not reported in this study, which are all part of caring for someone with MS or NMO, were not evaluated in this work, as well as teaching and research activities, an important part of a university hospital staff.

Demyelinating diseases demand a complex care which should be focused on early diagnosis and treatment with the intention to prevent neurologic disability. Considering that patients with NMO present a more debilitating disease within an earlier timeframe than patients with MS, the current work emphasizes the need of an early and correct diagnosis, since one should expect NMO prevalence be higher among Brazilians. The creation of a collaborative network to collect information on patient care should be the next step in order to update the prevalence of MS and NMO in the city of Sao Paulo and provide data to healthcare providers that could be used in future planning for public policies and patient care.

\section{ACKNOWLEDGEMENTS}

Authors would like to thank Mr. Alison Ferreira for the invaluable help in obtaining data from the hospital's system.

\section{References}

1. Adelman G, Rane SG, Villa KF. The cost burden of multiple sclerosis in the United States: a systematic review of the literature. J Med Econ. 2013;16(5):639-47. http://dx.doi.org/10.3111/13696998.2013.778268

2. Jacob A, McKeon A, Nakashima I, et al. Current concept of neuromyelitis optica (NMO) and NMO spectrum disorders. J Neurol Neurosurg Psychiatry. 2013;84(8):922-30. http://dx.doi.org/10.1136/jnnp-2012-302310

3. Lublin FD, Reingold SC. Defining the clinical course of multiple sclerosis: results of an international survey. Neurology. 1996;46(4):907-11. http://dx.doi.org/10.1212/WNL.46.4.907

4. Wingerchuk DM, Pittock SJ, Lucchinetti CF, Lennon VA, Weinshenker BG. A secondary progressive clinical course is uncommon in neuromyelitis optica. Neurology. 2007;68(8):603-5. http://dx.doi.org/10.1212/01.wnl.0000254502.87233.9a
Bichuetti DB, Oliveira EM, Souza NS, Rivero RL, Gabbai AA. Neuromyelitis optica in Brazil: a study on clinical and prognostic factors. Mult Scler. 2009;15(5):613-9. http://dx.doi.org/10.1177/1352458508101935

6. Polman CH, Reingold SC, Banwell B, Clanet M, Cohen JA, Filippi $M$ et al. Diagnostic criteria for multiple sclerosis: 2010 revisions to the McDonald criteria. Ann Neurol. 2011;69(2):292-302. http://dx.doi.org/10.1002/ana.22366

7. Wingerchuk DM, Lennon VA, Pittock SJ, Lucchinetti CF, Weinshenker BG. Revised diagnostic criteria for neuromyelitis optica. Neurology. 2006;66(10):1485-9. http://dx.doi.org/10.1212/01.wnl.0000216139.44259.74

8. Courtney AM, Treadaway K, Remington G, Frohman E. Multiple sclerosis. Med Clin North Am. 2009;93(2):451-76. http://dx.doi.org/10.1016/j.mcna.2008.09.014 
9. Kantarci O, Wingerchuk D. Epidemiology and natural history of multiple sclerosis: new insights. Curr Opin Neurol. 2006;19(3):24854. http://dx.doi.org/10.1097/01.wco.0000227033.47458.82

10. Callegaro D, Goldbaum M, Morais L, et al. The prevalence of multiple sclerosis in the city of Sao Paulo, Brazil, 1997. Acta Neurol Scand. 2001;104(4):208-13. http://dx.doi.org/10.1034/j.1600-0404.2001.00372.x

11. Lana-Peixoto MA, Frota ER, Campos GB, Monteiro LP, Brazilian Committee for Treatment and Research in Multiple Sclerosis. The prevalence of multiple sclerosis in Belo Horizonte, Brazil. Arq Neuropsiquiatr. 2012;70(2):102-107. http://dx.doi.org/10.1590/S0004-282X2012000200006

12. Bichuetti DB, Oliveira EM, Souza NA, Tintore M, Gabbai AA. Patients with neuromyelitis optica have a more severe disease than patients with relapsingremitting multiple sclerosis, including higher risk of dying of a demyelinating disease. Arq Neuropsiquiatr 2013;71(5):275-9. http://dx.doi.org/10.1590/0004-282X20130020

13. Brum DG, Barreira AA, Santos AC, Kaimen-Maciel DR, Mariello M, Costa RM et al. HLA-DRB association in neuromyelitis optica is different from that observed in multiple sclerosis. Mult Scler. 2010;16(1):21-9. http://dx.doi.org/10.1177/1352458509350741

14. Brum DG, Luizon MR, Santos AC, Lana-Peixoto MA, Rocha CF, Brito $M L$ et al. European ancestry predominates in neuromyelitis optica and multiple sclerosis patients from Brazil. PLoS ONE. 2013;8(3):e58925.

15. Matiello M, Schaefer-Klein J, Brum DG, Atkinson EJ, Kantarci OH, Weinshenker BG. HLA-DRB1*1501 tagging rs3135388 polymorphism is not associated with neuromyelitis optica. Mult Scler. 2010;16(8):981-4. http://dx.doi.org/10.1177/1352458510374340

16. World Health Organization, Multiple Sclerosis International Federation. Atlas: multiple sclerosis resources in the world 2008. Geneva: World Health Organization, 2008 [cited 2014 Mar 4]. Available at: http://www.who.int/mental_health/neurology/atlas_ multiple_sclerosis_resources_2008/en/

17. Ministério da Saúde (BR). Portaria $n^{\circ} 1.323$, de 25 de novembro de 2013. Aprova o protocolo clínico e diretrizes terapêuticas da esclerose múltipla. Diário Oficial da União. 27 nov 2013.

18. Miller DH, Weinshenker BG, Filippi M, Banwell BL, Cohen JA, Freedman MS et al. Differential diagnosis of suspected multiple sclerosis: a consensus approach. Mult Scler. 2008;14(9):1157-74.
19. Wingerchuk DM, Hogancamp WF, O'Brien PC, Weinshenker BG. The clinical course of neuromyelitis optica (Devic's syndrome). Neurology. 1999;53(5):1107-14. http://dx.doi.org/10.1212/WNL.53.5.1107

20. Trebst C, Jarius S, Berthele A, Paul F, Schippling S, Wildemannn B et al. Update on the diagnosis and treatment of neuromyelitis optica: Recommendations of the Neuromyelitis Optica Study Group (NEMOS). J Neurol. 2014;261(1):1-16. http://dx.doi.org/10.1007/s00415-013-7169-7

21. Krupp LB, Tardieu M, Amato MP, Banwell B, Chitnis T, Dale RC et al. International Pediatric Multiple Sclerosis Study Group criteria for pediatric multiple sclerosis and immune-mediated central nervous system demyelinating disorders: revisions to the 2007 definitions. Mult Scler. 2013;19(10):1261-7. http://dx.doi.org/10.1177/1352458513484547

22. Arias M, Dapena D, Arias-Rivas S, Costa E, López A, Prieto JM et al. Late onset multiple sclerosis. Neurologia. 2011;26(5):291-6. http://dx.doi.org/10.1016/j.nrl.2010.09.008

23. Río J, Comabella M, Montalban X. Multiple sclerosis: current treatment algorithms. Curr Opin Neurol. 2011;24(3):230-7. http:// dx.doi.org/10.1097/WC0.0b013e328346bf66

24. Bichuetti DB, Oliveira EM, Boulos FC, Gabbai AA. Lack of response to pulse cyclophosphamide in neuromyelitis optica: evaluation of 7 patients. Arch Neurol. 2012;69(7):938-9. http://dx.doi.org/10.1001/ archneurol.2012.545

25. Bichuetti DB, Boulos F, Shinosaki JS, Souza N, Oliveira E, Gabbai A. Treatment of neuromyelitis optica with intravenous immunoglobulin: report of 8 Patients. Neurology. 2012;78(Meeting Abstracts 1):P04.141. http://dx.doi.org/10.1212/WNL.78.1_MeetingAbstracts. P04.141

26. Bichuetti DB, Oliveira EML, Oliveira DM, Souza Na, Gabbai AA. Neuromyelitis optica treatment: analysis of 36 patients. Arch Neurol. 2010;67(9):1131-6. http://dx.doi.org/10.1001/archneurol.2010.203

27. Oliveira EML, Souza NA, Bichuetti DB, Oliveira DM, Annes M, Gabbai AA Multiple sclerosis in Brazil: 1994-2005, a Brazilian experience. In: 22nd Congress of the European Committee for Treatment and Research in Multiple Sclerosis (ECTRIMS); 2006; Madrid. Madri: SAGE; 2006.

28. Belman A, Chabas D, Chitnis T, et al. Clinical spectrum of diagnoses in children referred for evaluation of acquired CNS demyelinating disorders including pediatric multiple sclerosis. Ann Neurol. 2007;62. 